\title{
A cross-sectional observation on habitual non-alcoholic beverage consumption among adolescents from four Irish post-primary schools
}

\author{
Sophie Millar ${ }^{1, *}$, Megan O'Donoghue ${ }^{1,2}$, Breige McNulty ${ }^{1}$, Laura Kirwan ${ }^{1,2}$ \\ and Aideen McKevitt ${ }^{1}$ \\ ${ }^{1}$ School of Agriculture and Food Science, University College Dublin, Belfield, Dublin 4, Republic of Ireland: \\ ${ }^{2}$ School of Biomedical Sciences, University of Ulster, Coleraine, Londonderry, UK
}

Submitted 17 November 2015: Final revision received 9 September 2016: Accepted 24 August 2016: First published online 26 September 2016

\begin{abstract}
Objective: No up-to-date data on the dietary intake of Irish adolescents are available. The aim of the present pilot study was to obtain and compare cross-sectional information on habitual adolescent beverage consumption between four distinct post-primary schools in the Republic of Ireland, in 2014-2015.

Design: A cross-sectional observation study. A beverage consumption questionnaire was used to obtain data on beverage intake and influences on consumption.

Setting: Four post-primary mixed-sex schools in Ireland representing the following school classifications were selected for the study: urban fee-paying, urban disadvantaged, rural fee-paying and rural disadvantaged.

Subjects: Students ( $n$ 761) aged $12-18$ years.

Results: Data were analysed by Kruskal-Wallis (non-parametric) ANOVA to compare the distribution of beverage consumption across the schools. Water was the most highly consumed beverage among students from all four schools (median $1425 \mathrm{ml} / \mathrm{d}$ ). Students from urban and rural disadvantaged schools reported a significantly higher volume of carbonated beverage intake than students from fee-paying schools. Students from an urban disadvantaged school also reported a significantly higher volume of carbonated beverage and energy drink intake compared with the other three schools. Students from an urban fee-paying school reported the highest consumption of water, while rural disadvantaged school students were the biggest consumers of tea and milk.

Conclusions: Significant differences in beverage consumption $(\mathrm{ml} / \mathrm{d})$ were reported by adolescents from four schools in Ireland. Surveillance on current beverage consumption trends among adolescents is vital to guide policies and interventions, and for appropriate targeting of resources.
\end{abstract}

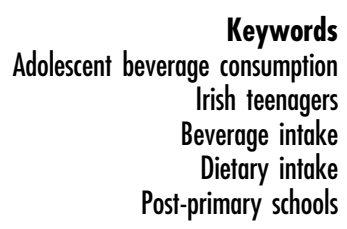

Beverage consumption is a significant contributor to daily energy intake, but is often overlooked as a component of dietary intake by individuals ${ }^{(1)}$. Hydration and fluid intake are fundamental to daily living and health, and contribute to physiological homeostasis ${ }^{(2)}$. The United Nations has estimated that every person drinks $2-4$ litres of water per day ${ }^{(3)}$. A global systematic review of fluid intake from beverages across age groups reported that total beverage intake was in the range of $0 \cdot 6-1 \cdot 8,0 \cdot 8-2 \cdot 0$ and $0 \cdot 8-3 \cdot 4$ litres per day for children, teenagers and adults, and water consumption accounted for 58, 75 and $80 \%$ of total fluid intake, respectively $^{(4)}$. Singh et al. reported that average global daily intakes of sugar-sweetened beverages (SSB), fruit juice and milk in adults were 132, 36 and $130 \mathrm{ml}$, respectively, in $2010^{(5)}$.
Dietary intake and nutrition are strong determinants of health and chronic non-communicable diseases throughout life ${ }^{(6)}$. It has been estimated that by 2030, 69\% of all deaths worldwide will be attributable to noncommunicable diseases ${ }^{(7)}$. An increase in the prevalence of adult diseases such as obesity, type 2 diabetes, CVD, metabolic syndrome and fatty liver disease has been reported among adolescents ${ }^{(8-11)}$, hence this age group is under scrutiny in terms of dietary intake.

Sugar intake, including intake from SSB, has come under the spotlight in recent years with revised intake recommendations from expert bodies such as the WHO and the UK Scientific Advisory Committee on Nutrition ${ }^{(12,13)}$. A number of studies and meta-analyses have found a 
positive association between SSB consumption and weight, as is concluded by the Committee in its Carbobydrates and Health report ${ }^{(13-19)}$. Substantial evidence indicates that SSB have a low satiating effect, leading to greater energy intake than required ${ }^{(15,20,21)}$. The Scientific Advisory Committee on Nutrition report further acknowledged an increased risk of tooth decay and type 2 diabetes with increased SSB consumption, and recommended that consumption of SSB is minimised in both children and adults ${ }^{(13)}$. Singh et al. estimated that 184000 adult deaths worldwide in 2010 were attributable to SSB alone ${ }^{(22)}$. However, a recent review has reported an overall decrease or stabilisation in sugar intake in developed countries ${ }^{(23)}$.

Food and beverage choices result from a variety of determinants $^{(24)}$. Influences include biological factors, socio-economic factors, psychological factors and external factors such as marketing. Beverage consumption and beverage choice are also strongly related to age and sex ${ }^{(25)}$. Knowledge about sugars in beverages is an important factor influencing beverage consumption in adults $^{(26)}$. However, parental influence and home environments have been shown to play more of a central role in beverage choice in adolescents and children ${ }^{(27,28)}$

The National Teens' Food Survey (NTFS), conducted in 2005-2006, was the last study to collect information on adolescent beverage consumption in the Republic of Ireland $^{(29)}$. It was a comprehensive study to collect information primarily on dietary intake in order to develop nutrition policies and health promotion campaigns. The NTFS reported water, milk and carbonated beverages as the three most highly consumed beverages. The present pilot study in 2014-2015 aimed to obtain up-to-date cross-sectional information on habitual non-alcoholic beverage consumption among a sample of 12-18-year-olds.

The Department of Education and Skills in Ireland addresses educational disadvantage in disadvantaged communities through implementing an action plan called 'DEIS' (Delivering Equality of Opportunity in Schools). This programme is designed to provide a number of supports such as a School Meals Programme or School Books Grant Scheme. The current study included adolescents from two DEIS schools and two fee-paying schools in urban and rural Ireland in order to reveal any differences by school type. This is important in the context of research that has reported widening health inequalities among adolescents in Ireland ${ }^{(30,31)}$. A further aim of the present research was to gain insight into some of the influences on adolescent beverage consumption.

\section{Methods}

\section{Sampling}

Between November 2014 and May 2015, teenagers aged 12-18 years from four post-primary schools in the Republic of Ireland were invited to take part in the study. Schools were selected from a database of post-primary schools available from the Department of Education and Skills in Ireland. A convenience sample of four mixed-sex schools was selected to represent the following categories: urban fee-paying, urban DEIS, rural fee-paying and rural DEIS. The four schools invited participated in the study. A power calculation was not performed due to the pilot nature of the study. The study was approved by the Human Research Ethics Committee of University College Dublin and written informed consent was obtained from participating adolescents and their parents.

\section{Respondent recruitment}

An introductory letter and information about the questionnaire were sent to the principal of each of the four schools that agreed to participate in the questionnaire. Researchers met with an assigned teacher from each school to help coordinate the study. An information pack, which included an information letter and parental/ guardian consent form, was distributed to students within each school. Students aged 12-18 years who returned signed parental/guardian consent forms were eligible for the study.

\section{Questionnaire design}

An anonymous and self-administered questionnaire was designed for the present study. The questionnaire was divided into three sections. The first section was designed to obtain information on the age and sex of the student. The second section was designed to determine frequency of beverage consumption and usual serving sizes. Beverage categories included were modelled on those used in previous studies such as Food $4 \mathrm{Me}^{(32)}$, the European Prospective Investigation into Cancer and Nutrition $^{(33)}$ and the Irish Universities Nutrition Alliance studies $^{(29,34-36)}$. In addition, for the current study beverage categories were expanded to reflect the current Irish market. Table 1 lists all beverage categories used within the study. Ten frequency options for beverage consumption were given, ranging from 'never' to ' $>6$ times per day'. Serving sizes were based on household measures and supermarket products. Photographs of serving sizes were provided within the questionnaire for students to aid estimation of intake. The third section of the questionnaire concerned the existence of parental rules surrounding non-alcoholic beverages (yes/no), frequency of purchasing beverages during school breaks ('every day', '3-4 times per week', '1-2 times per week', 'less than once per week', 'never'), home availability of beverage categories ('never', 'sometimes', 'usually', 'always') and perception of the best way to learn about healthy drinks (advertisements on television/radio, posters in school, parents/guardians, teachers, friends, Facebook and other social media, a health professional: 'strongly disagree', 'disagree', 'neither disagree or agree', 'agree', 'strongly agree'). Participating schools were requested to provide information about their policies or rules surrounding the 
Table 1 Beverage consumption categories and sub-categories within the present questionnaire $\dagger$

\begin{tabular}{ll}
\hline Main category & Sub-categories \\
\hline Carbonated beverages & Carbonated beverages \\
& Diet, zero- or low-calorie versions of carbonated beverages \\
Water drinks & Energy drinksł \\
& Water \\
& Coconut water \\
& Flavoured water \\
& Vitamin water \\
& Slushies \\
& Fruit juices \\
Juices and smoothies & Tomato juice or other vegetable juices \\
& Smoothies \\
& Fruit squash or cordials (made up with water) \\
Teas and coffees & Tea \\
& Coffee \\
& Decaffeinated coffee \\
& Iced tea or coffee \\
& Herbal tea \\
Milk drinks & Milk (not in cereal or tea/coffee) \\
& Cot chocolate (made with milk) \\
& Chocolate or fruit-flavoured milk drinks \\
& Horlicks, Ovaltine \\
Milkshakes \\
Yoghurt or probiotic drinks
\end{tabular}

†Categories were based on those use in previous national and European research projects and expanded to reflect the current Irish market: Food4Me ${ }^{(32)}$, the European Prospective Investigation into Cancer and Nutrition ${ }^{(33)}$ and the Irish Universities Nutrition Alliance studies ${ }^{(29,34-36)}$.

‡Refers to both diet and non-diet versions of energy drinks.

sale and consumption of beverages on school premises, and lunchtime policies.

\section{Data collection and data management}

The questionnaire was piloted on a sample of adolescents aged 12-18 years old, independent of the schools included in the study sample, to identify any issues or misinterpretations of the questions. The questionnaires were completed under supervision of school teachers in a classroom setting. To ensure anonymity and encourage honesty the students had no contact with the researchers. Questionnaire sections that had been fully completed (91\%) were included in the final analysis to ensure data quality and consistency in reporting.

A standard operating procedure was adhered to for data entry for all responses, including ambiguous responses (e.g. if two answers were provided where only one was required). Questionnaire data were hand entered into a database using a data dictionary. For quality control purposes, half of the paper questionnaires were checked by an additional nutrition researcher.

\section{Statistical analyses}

Consumption was calculated from indicated frequency per day and corresponding serving size (millilitres) for each beverage. The middle value for the indicated frequency category was taken; for example, where a student indicated $\mathrm{s} /$ he consumed a beverage $2-4$ times per month, this was taken as 3 times per month. The categories ' $<1$ time per month' was taken as ' 0.5 times per month' and the category '>6 times per day' was taken as ' 7 times per day'.
Data were not normally distributed, thus a nonparametric Kruskal-Wallis test was used to compare the consumption distribution for each beverage across the four schools. Where the overall test was significant, pairwise comparisons were used to identify which schools differed. $P$ values were adjusted to control the family-wise type 1 error. For four tests, this resulted in a multiplier of $(4 \times 3) / 2=6$. Adjusted $P$ values are significant at $P_{\text {adj }}<0.05$ (at the $\alpha=0.05 / 6=0.00833$ level). The distribution of the home availability of the different categories was compared across schools using a $\chi^{2}$ test for each beverage. The $\chi^{2}$ test was also used to compare the distributions of categories concerning the best way to learn about healthy drinks and parental rules regarding beverages. A Kruskal-Wallis test was used to assess beverage consumption across groups organised by beverage purchasing frequency. Statistical analyses were performed using the statistical software package IBM SPSS Statistics for Windows Version 20.0.

\section{Results}

\section{Beverage consumption}

Sample characteristics and response rates are presented in Table 2 . The overall response rate was $82.5 \%$. The following beverage categories were included in the analyses: diet, zero- or low-calorie versions of carbonated beverages (hereafter referred to as 'diet carbonated beverages'); carbonated beverages; energy drinks; water; flavoured water; fruit juice; smoothies; fruit squash; tea; milk; hot chocolate; and milkshakes. Coconut water, vitamin water, 
Table 2 Characteristics of adolescents $(n$ 761) aged $12-18$ years from four post-primary schools in the Republic of Ireland, 2014-2015.

\begin{tabular}{lccccc}
\hline & \multicolumn{4}{c}{ School type } \\
\cline { 2 - 5 } & Urban DEIS† & Urban fee-paying & Rural DEIS† & Rural fee-paying & Total \\
\hline Sample size & 189 & 210 & 170 & 192 & 761 \\
Mean age (years) & 14.0 & 14.8 & 14.7 & 14.6 & 14.5 \\
Male (\%) & 56 & 43 & 55 & 53 & 51 \\
Response rate (\%) & 73 & 97 & 78 & 86 & 82.5 \\
\hline
\end{tabular}

†DEIS (Delivering Equality of Opportunity in Schools) designates a school within a disadvantaged community.

Table 3 Reported median, lower quartile (LQ) and upper quartile (UQ) consumption ( $\mathrm{ml} / \mathrm{d}$ ) of beverage categories by adolescents ( $n$ 761) aged 12-18 years from four post-primary schools in the Republic of Ireland, 2014-2015, presented as total and by sex. Age correlation coefficients and significant differences in consumption between sexes are also presented.

\begin{tabular}{|c|c|c|c|c|c|c|c|c|}
\hline \multirow[b]{2}{*}{ Beverage } & \multicolumn{2}{|c|}{ Total $(n 761)$} & \multirow{2}{*}{$\begin{array}{l}\text { Age correlation } \\
\text { coefficient† }\end{array}$} & \multicolumn{2}{|c|}{ Male ( $n$ 388) } & \multicolumn{2}{|c|}{ Female ( $n$ 373) } & \multirow[b]{2}{*}{$P$ value $\neq$} \\
\hline & Median & LQ-UQ & & Median & LQ-UQ & Median & LQ-UQ & \\
\hline Diet carbonated beverages§ & $10 \cdot 0$ & $0.0-46 \cdot 2$ & $-0 \cdot 10^{*}$ & $10 \cdot 0$ & $0.0-65.8$ & $10 \cdot 0$ & $0.0-46 \cdot 2$ & 0.659 \\
\hline Carbonated beverages & $35 \cdot 0$ & $10 \cdot 0-141.9$ & -0.06 & $70 \cdot 0$ & $23 \cdot 1-215 \cdot 0$ & $28 \cdot 0$ & $6 \cdot 6-86 \cdot 0$ & $<0.001$ \\
\hline Energy drinks\| & $10 \cdot 0$ & $0.0-70.0$ & 0.02 & $17 \cdot 5$ & $0.0-70.0$ & $7 \cdot 6$ & $0.0-35 \cdot 0$ & $<0.001$ \\
\hline Water & $1425 \cdot 0$ & $750 \cdot 0-2565 \cdot 0$ & $0.01^{* *}$ & $1425 \cdot 0$ & $750 \cdot 0-2565 \cdot 0$ & $1425 \cdot 0$ & $900 \cdot 0-3375 \cdot 0$ & 0.694 \\
\hline Flavoured water & $10 \cdot 0$ & $0.0-52.5$ & $-0 \cdot 14^{\star \star}$ & $10 \cdot 0$ & $0.0-70.0$ & 5.5 & $0.0-38.5$ & 0.694 \\
\hline Fruit juice & $86 \cdot 0$ & $14 \cdot 0-200 \cdot 0$ & -0.04 & $86 \cdot 0$ & $17 \cdot 5-200 \cdot 0$ & $86 \cdot 0$ & $14 \cdot 0-200 \cdot 0$ & 0.007 \\
\hline Smoothies & 11.4 & $0 \cdot 0-39 \cdot 2$ & 0.04 & $5 \cdot 0$ & $0 \cdot 0-28 \cdot 0$ & $11 \cdot 4$ & $0.0-39.9$ & 0.003 \\
\hline Fruit squash & $14 \cdot 0$ & $0.0-200.0$ & 0.04 & 14.0 & $0.0-200.0$ & 14.0 & $0.0-158.0$ & 0.552 \\
\hline Tea & $129 \cdot 0$ & $0.0-300.0$ & 0.06 & 129.0 & $0.0-300.0$ & $129 \cdot 0$ & $0.0-300.0$ & 0.587 \\
\hline Milk & $42 \cdot 0$ & $0.0-200.0$ & 0.01 & 158.0 & $14.0-356 \cdot 4$ & $14 \cdot 0$ & $0.0-86 \cdot 0$ & $<0.001$ \\
\hline Hot chocolate & 9.5 & $4 \cdot 0-42 \cdot 0$ & $-0 \cdot 13^{\star *}$ & $6 \cdot 0$ & $0.0-31.9$ & $21 \cdot 0$ & $6 \cdot 0-42 \cdot 0$ & 0.015 \\
\hline Milkshakes & 4.0 & $0 \cdot 0-14.0$ & $-0.11^{\star}$ & 4.0 & $0 \cdot 0-14.0$ & 4.0 & $0.0-14.0$ & 0.098 \\
\hline
\end{tabular}

${ }^{*}$ Correlation is significant at the 0.05 level (two-tailed).

${ }^{* *}$ Correlation is significant at the 0.01 level (two-tailed).

†Spearman's correlations.

$\ddagger P$ value presented is for the Mann-Whitney test for a difference in distribution in beverage consumption across sex.

$\S$ Diet, zero- or low-calorie versions of carbonated beverages.

IIRefers to both diet and non-diet versions of energy drinks.

slushies, vegetable juice, coffee, decaffeinated coffee, iced tea or coffee, herbal tea, flavoured milk, Horlicks/Ovaltine and yoghurt drinks were reported with a median frequency of consumption of 'never' by the total population, and thus were excluded from the main analyses.

Table 3 presents the median, lower quartile and upper quartile of beverage consumption $(\mathrm{ml} / \mathrm{d})$ for the total sample population. Water $(1425 \mathrm{ml} / \mathrm{d})$, tea $(129 \mathrm{ml} / \mathrm{d})$ and fruit juice $(86 \mathrm{ml} / \mathrm{d})$ were the top three most consumed drinks. These were followed by milk $(42 \mathrm{ml} / \mathrm{d})$ and carbonated beverages $(39 \mathrm{ml} / \mathrm{d})$, while all other categories were reported at $<15 \mathrm{ml} / \mathrm{d}$. A number of weak associations of beverage consumption with age were reported (Table 3). Diet carbonated beverage, flavoured water, hot chocolate and milkshake consumption all decreased with increasing age $(P<0.05)$, while water was the only beverage to increase with age $(P<0 \cdot 01)$. Significant differences in beverage consumption were also reported by sex (Table 3). Carbonated beverages and energy drinks were consumed significantly more by males than females $(P<0 \cdot 001)$, while smoothies were consumed significantly more by females than males $(P<0 \cdot 01)$. Milk was consumed more by males $(P<0 \cdot 001)$; however, females reported higher consumption of hot chocolate $(P<0 \cdot 05)$.

Table 4 presents the median, lower quartile and upper quartile of beverage consumption $(\mathrm{ml} / \mathrm{d}$ ) across the four schools, and the significant differences between them. In all four schools the highest consumption was reported for water. Urban fee-paying school students reported the highest median consumption of water $(1875 \mathrm{ml} / \mathrm{d})$, significantly more than urban DEIS and rural fee-paying school students $(P<0 \cdot 01)$. Flavoured water consumption significantly differed between the four schools with the highest median consumption $(35 \mathrm{ml} / \mathrm{d})$ reported by urban DEIS school students $(P<0 \cdot 001)$. Urban DEIS school students reported a significantly higher consumption of diet carbonated beverages, carbonated beverages and energy drinks (median 46.2, 163.4 and $70 \mathrm{ml} / \mathrm{d}$, respectively; $P<0.001$ ) compared with all other schools. Rural DEIS school students reported a significantly lower consumption of fruit juice $(39.9 \mathrm{ml} / \mathrm{d})$ compared with the other schools $(P<0 \cdot 001)$, but reported the highest consumption of fruit squash. Rural DEIS school students were the biggest consumers of tea and milk (median 237 and 
$86 \mathrm{ml} / \mathrm{d}$, respectively), with a significantly higher amount $(P \leq 0.001)$ than urban fee-paying school students who consumed the least amount of tea and milk overall (median 21 and $14 \mathrm{ml} / \mathrm{d}$, respectively).

\section{Influences}

Overall, $26.5 \%$ of students reported that their parents had rules regarding non-alcoholic beverage consumption. Those who reported their parents/guardians as having rules consumed significantly less carbonated beverages and energy drinks than those who did not have rules $(P<0 \cdot 001$; Table 5).

Only students from the urban DEIS school were allowed outside the school premises during school breaks. Almost $55 \%$ of these students reported that they go to a shop at break times and purchase beverages at least once per week, while $33.7 \%$ never purchased beverages or do not have permission. As expected, consumption of carbonated beverages and energy drinks differed significantly across purchasing frequency groups $(P<0 \cdot 001)$. For example, an almost threefold increase in carbonated beverage consumption was reported between those who reported never purchasing beverages and those who reported purchasing beverages every day.

Water, tea/coffee and milk were reported as the three most commonly available beverages at home. Across the schools, significant differences were reported for carbonated beverage home availability $(P<0 \cdot 001$; Fig. 1$)$. Carbonated beverages were reported as sometimes or always available at home by $75.8 \%$ of urban DEIS school students, $29.3 \%$ of urban fee-paying school students, $50.0 \%$ of rural DEIS students and $35.0 \%$ of rural fee-paying students. A similar trend was reported with diet carbonated beverages $(P<0.01)$. Yoghurt or probiotic drink availability was significantly different across the schools $(P<0 \cdot 001)$, reported as always available by $32.3 \%$ of urban DEIS students, $13.8 \%$ of urban fee-paying students, $20.2 \%$ of rural DEIS students and $19.0 \%$ of rural fee-paying students.

'Health professionals' was the most popular option selected by students when asked about the best way to learn about healthy drinks ( $66 \%$ agreed or strongly agreed), while advertisements on television/radio and posters in school were the least popular options chosen by students (Fig. 2). Overall, 39.0\% of students agreed or strongly agreed that the best way to learn about healthy drinks was through friends. However, significantly fewer students (33.4\%) from the urban DEIS school agreed with this option $(P<0.05)$ compared with the other schools (44.0, 46.0 and $40.6 \%$ for urban fee-paying, rural fee-paying and rural DEIS schools, respectively).

\section{Discussion}

In the current study, adolescents from four post-primary schools in the Republic of Ireland reported water 
Table 5 Median consumption $(\mathrm{ml} / \mathrm{d})$ of carbonated, diet carbonated and energy drinks by adolescents $(n 761)$ aged 12-18 years from four post-primary schools in the Republic of Ireland, 2014-2015, according to report of their parents/ guardians having rules surrounding non-alcoholic beverages.

\begin{tabular}{lccr}
\hline Rules & Rules $(n$ 208) & No rules $(n$ 577) & $P$ value† \\
\hline Diet carbonated beverages $\ddagger$ & 6.6 & 7.6 & 0.121 \\
Carbonated beverages & 15.0 & 46.2 & $<0.001$ \\
Energy drinks§ & 5.0 & 10.0 & $<0.001$ \\
\hline
\end{tabular}

$\dagger P$ value presented is for the Kruskal-Wallis test for a difference in beverage consumption according to the presence/absence of rules. The responses to whether parents/guardians had rules surrounding beverages (yes/no) were also compared across schools using a $\chi^{2}$ test. Fee-paying school students reported a significantly higher proportion of 'yes' responses than DEISII school students $(P<0.008)$. $\ddagger$ Diet, zero- or low-calorie versions of carbonated beverages.

§Refers to both diet and non-diet versions of energy drinks.

IIDEIS (Delivering Equality of Opportunity in Schools) designates a school within a disadvantaged community.

(a)

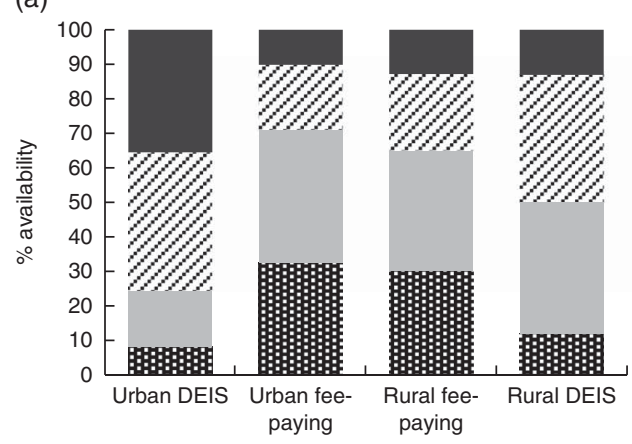

(c)

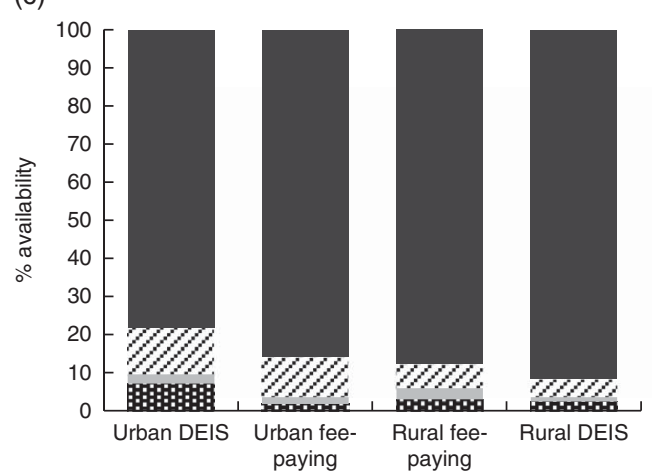

(b)

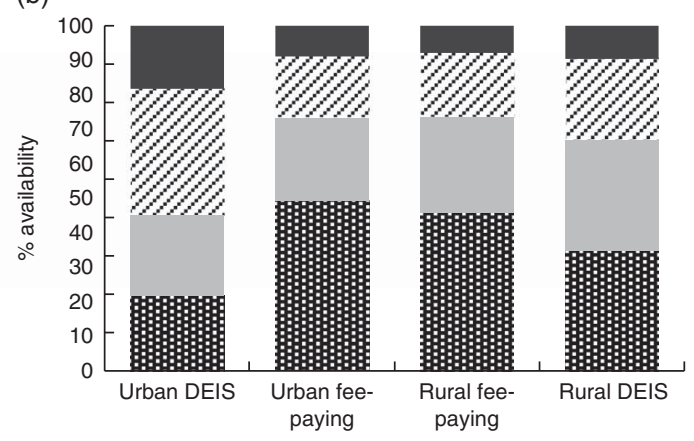

(d)

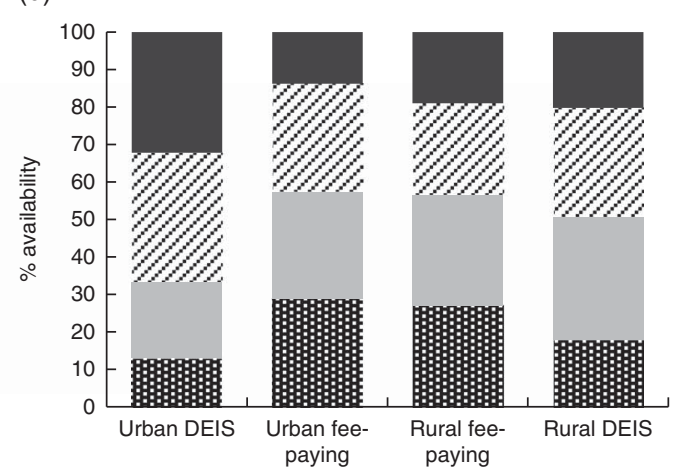

Fig. 1 The reported percentage availability ( $\square$, always available; $₫$, sometimes available; $\square$, not usually available; 眀, never available) of (a) carbonated beverages, (b) diet, zero- or low-calorie versions of carbonated beverages, (c) tea and coffee, and (d) yoghurt and probiotic drinks within the home setting by adolescents ( $n$ 761) aged 12-18 years from four post-primary school types in the Republic of Ireland, 2014-2015. The distribution of the home availability categories was compared across schools using a $\chi^{2}$ test for each beverage; all beverages were significantly different at $P_{\text {adj }}<0.05$ (at the $a=0.05 / 6=0.00833$ level; DEIS (Delivering Equality of Opportunity in Schools) designates a school within a disadvantaged community)

$(1425 \mathrm{ml} / \mathrm{d})$, tea $(129 \mathrm{ml} / \mathrm{d})$ and fruit juice $(86 \mathrm{ml} / \mathrm{d})$ as the top three most consumed beverages. This is in contrast to the data reported in the NTFS 2005-2006, where water $(317 \mathrm{ml} / \mathrm{d})$, tea $(31 \mathrm{ml} / \mathrm{d})$ and fruit juice $(43 \mathrm{ml} / \mathrm{d})$ were reported as the first, fifth and fourth most consumed beverages, respectively ${ }^{(29)}$. Carbonated beverages were reported as the third most highly consumed beverage in the NTFS $(129 \mathrm{ml} / \mathrm{d})^{(29)}$. Consumption of carbonated beverages was relatively low in the current study (fifth most highly consumed, median consumption $39 \mathrm{ml} / \mathrm{d}$ ) compared with the NTFS ${ }^{(29)}$. The present study's questionnaire was conducted between November and May; therefore seasonality may have had an effect on beverage consumption estimates. A trend of increased milk consumption in winter and increased juice consumption in summer has been observed ${ }^{(37)}$.

Carbonated beverage, energy drink and milk consumption was reported higher in males than females. These findings are similar to those from the NTFS in which carbonated beverage and milk consumption was reported as higher in males than in females ${ }^{(29)}$. Carbonated beverage consumption is also widely reported in other literature as higher in males than females ${ }^{(38-40)}$. Diet carbonated beverage, flavoured water, hot chocolate and 


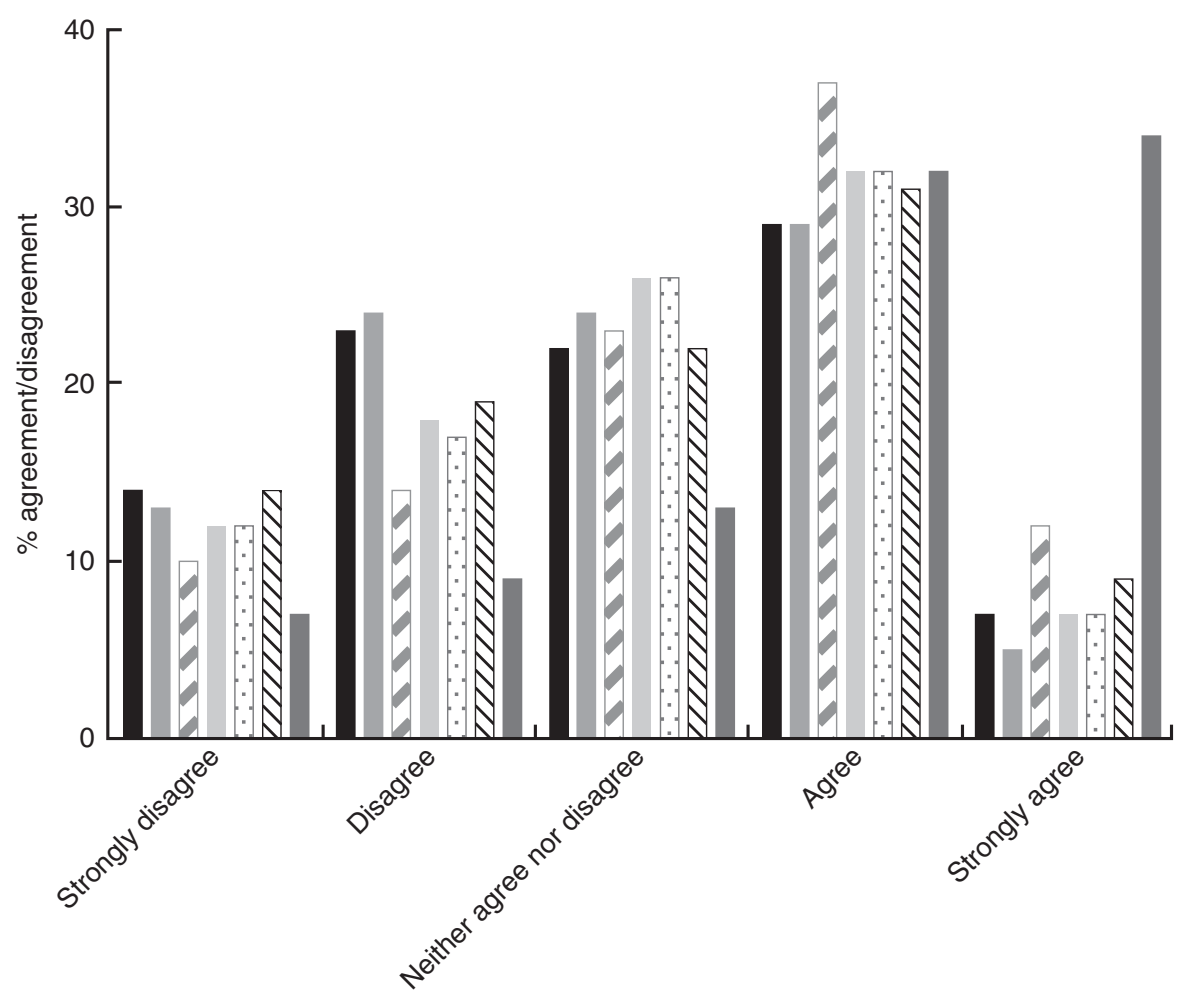

Fig. 2 The percentage of agreement and disagreement by adolescents $(n 761)$ aged $12-18$ years from four post-primary schools in the Republic of Ireland, 2014-2015, with the following options as being the best source to learn about healthy beverages:

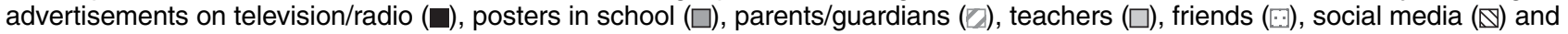
health professionals $(\square)$

milkshake consumption decreased significantly with increasing age, whereas water consumption increased. Nutritionists and other health-care and policy workers may need to consider age and sex influences in order to elicit an effective campaign on promoting healthy beverage consumption.

It was recently demonstrated that the health inequalities are widening among adolescents in a number of countries, including Ireland ${ }^{(30)}$. Heinen et al. demonstrated a stabilisation or reduction in the prevalence of overweight and obesity among children in Ireland from 2008 to $2012^{(31)}$. However, this trend was not seen among children attending DEIS schools ${ }^{(31)}$. In the present study, students in the DEIS schools (rural and urban) consumed higher amounts of carbonated beverages, diet carbonated beverages and energy drinks than students from feepaying schools (rural and urban). Water consumption was highest among fee-paying school students (rural and urban). While these findings align with literature reports that adolescents of parents with low occupation status have a higher intake of carbonated beverages than those with parents of a higher occupation status ${ }^{(41)}$, milk consumption was lowest among urban fee-paying school students and highest among rural DEIS school students. This finding conflicts with a meta-analysis of eighty-eight studies which reported decreased milk intake with increased SSB consumption ${ }^{(16)}$. Perhaps the different outcome reported here might be due to varying perceptions about the health properties of milk or a trend change since the meta-analysis was published in $2007^{(42)}$.

School policies can help to prevent childhood obesity and can influence students' attitudes towards nutrition ${ }^{(43)}$. The four schools in the current study stated that they discouraged students from bringing in carbonated beverages and restricted sales on the school premises. Neither rural schools nor the urban fee-paying school permitted students to leave the premises at lunchtime. However, at the particular urban DEIS school, students were required to leave the school premises during lunch break, leaving ample opportunity to visit local shops where they could obtain carbonated beverages. This policy may account for the relatively higher consumption of carbonated beverages by urban DEIS school students than fee-paying students, as $54.6 \%$ of urban DEIS students purchased beverages outside the school premises at least once weekly at break times.

Family habits and parenting style have been linked previously with carbonated beverage consumption in adolescents $^{(44,45)}$. Findings from the present study also indicate that parental rules may be an important factor contributing to beverage consumption. Students who reported presence of parental rules about non-alcoholic beverages also reported lower consumption of carbonated beverages and energy drinks compared with those who 
reported no parental rules. Home availability has also previously been associated with carbonated beverage consumption in adolescents ${ }^{(27,46,47)}$. The current study confirms these findings because when home availability was higher, so was reported consumption. The home environment has been suggested as a suitable setting for interventions that aim to reduce socio-economic inequalities in SSB consumption ${ }^{(48)}$.

An important preliminary finding from the present study in terms of campaign tactics is that students chose health professionals and parents/guardians as the best way to learn about healthy drinks. This is similar to findings from other research undertaken in Ireland which showed that schools, doctors and dentists were key informants regarding nutrition information ${ }^{(1)}$. The findings from the current analysis indicate that future approaches should incorporate health professionals and families in campaigns in order to relate best to adolescents.

There is a lack of validated beverage consumption assessment methods available for administration to 12-18year-olds from different ethnic/cultural origins ${ }^{(49,50)}$. Our questionnaire was therefore designed to incorporate many beverage types to accurately reflect the current Irish market. One of the limitations of the present study is the use of self-reported data from adolescents. Misreporting is a major problem in dietary assessment among adolescents, mostly through under-reporting, and data should be interpreted with caution ${ }^{(51)}$. In order to minimise misreporting, students were provided with a wide range of frequency categories from which to choose and photographs to aid in the selection of portion sizes. In addition, the analysis was run using the middle beverage consumption frequency value as well as the higher frequency value (data not presented). For example, if the frequency option '2-4 times per week' was selected this was taken as ' 3 times per week' and a second analysis was conducted taking ' 4 times per week' as the value. The results produced from the second analysis were very similar to those from the first. Carbonated beverage consumption increased when the higher value was used, and it then replaced milk as the fourth most commonly consumed beverage instead of the fifth. However, its median consumption $(46.2 \mathrm{ml} / \mathrm{d})$ was still much lower than that reported in the NTFS $(129 \mathrm{ml} / \mathrm{d})$. No data were collected on non-participants and therefore differences between responders and non-responders were not identified; however, the overall response rate was $82.5 \%$.

\section{Conclusion}

The present pilot study provides a snapshot of current habitual non-alcoholic beverage consumption among a sample of 12-18-year-olds in Ireland. Significant differences in beverage consumption were reported between adolescents from four distinct schools. While the results of the pilot study are not representative of the general population, they nevertheless indicate changing patterns of beverage consumption in Irish adolescents and suggest the need for action to promote healthy beverage consumption in disadvantaged areas. Further investigation in a larger nationally representative sample is needed to more fully understand the changing pattern of beverage consumption in this population.

\section{Acknowledgements}

Financial support: This research received partial funding from the School of Agriculture and Food Science, University College Dublin, Ireland. Conflict of interest: None. Authorship: A.M. formulated the research question and designed the study with S.M., who designed the survey format. S.M. and M.O. coordinated the survey completion in respective schools. L.K. and B.M. ran the statistical analyses and all authors contributed to analysing and interpreting the data. S.M. wrote the article with contributions from all authors. Ethics of buman subject participation: This study was conducted according to the guidelines laid down in the Declaration of Helsinki and all procedures involving human subjects were approved by the Human Research Ethics Committee at University College Dublin. Written informed parental consent was obtained for all participants.

\section{References}

1. safefood (2009) Drinks: Consumer knowledge and practice in relation to drinks for children and young people. http://www.safefood.eu/SafeFood/media/SafeFoodLibrary/ Documents/Publications/Research\%20Reports/9650_Drinks_ Interior-Cover.pdf (accessed September 2016).

2. EFSA Panel on Dietetic Products Nutrition and Allergies (2010) Scientific opinion on dietary reference values for water. EFSA J 8, 1459 .

3. United Nations (2013) Water for Food. http://www.unwater. org/fileadmin/user_upload/watercooperation2013/doc/Fact sheets/water_for_food.pdf (accessed Sepetermber 2015).

4. Ozen AE, Bibiloni MD, Pons A et al. (2015) Fluid intake from beverages across age groups: a systematic review. J Hum Nutr Diet 28, 417-442.

5. Singh GM, Micha R, Khatibzadeh S et al. (2015) Global, regional, and national consumption of sugar-sweetened beverages, fruit juices, and milk: a systematic assessment of beverage intake in 187 countries. PLoS One 10, e0124845.

6. World Health Organization (2002) The World Health Report 2002 - Reducing Risks, Promoting Healthy Life. Geneva: WHO.

7. Mathers CD \& Loncar D (2006) Projections of global mortality and burden of disease from 2002 to 2030. PLoS Med 3, e442.

8. Goran MI, Ball GD \& Cruz ML (2003) Obesity and risk of type 2 diabetes and cardiovascular disease in children and adolescents. J Clin Endocrinol Metab 88, 1417-1427.

9. de Ferranti S, Gauvreau K, Ludwig D et al. (2004) Prevalence of the metabolic syndrome in American adolescents. Circulation 110, 2494-2497.

10. Schwimmer JB, Deutsch R, Kahen T et al. (2006) Prevalence of fatty liver in children and adolescents. Pediatrics 118, 1388-1393. 
11. Perrin J, Bloom S \& Gortmaker S (2007) The increase of childhood chronic conditions in the United States. JAMA 297, 2755-2759.

12. World Health Organization (2014) Draft Guideline: Sugar Intakes for Adults and Children. Geneva: WHO.

13. Scientific Advisory Committee on Nutrition (2015) Carbohydrates and Health. London: TSO.

14. Malik VS, Pan A, Willett WC et al. (2013) Sugar-sweetened beverages and weight gain in children and adults: a systematic review and meta-analysis. Am J Clin Nutr 98, 1084-1102.

15. Te Morenga LA, Howatson AJ, Jones RM et al. (2014) Dietary sugars and cardiometabolic risk: systematic review and metaanalyses of randomized controlled trials of the effects on blood pressure and lipids. Am J Clin Nutr 100, 65-79.

16. Vartanian LR, Schwartz MB \& Brownell KD (2007) Effects of soft drink consumption on nutrition and health: a systematic review and meta-analysis. Am J Public Health 97, 667-675.

17. de Ruyter JC, Olthof MR, Seidell JC et al. (2012) A trial of sugar-free or sugar-sweetened beverages and body weight in children. $N$ Engl J Med 367, 1397-1406.

18. Malik VS, Schulze MB \& Hu FB (2006) Intake of sugarsweetened beverages and weight gain: a systematic review. Am J Clin Nutr 84, 274-288.

19. Ebbeling CB, Feldman HA, Chomitz VR et al. (2012) A randomized trial of sugar-sweetened beverages and adolescent body weight. $N$ Engl J Med 367, 1407-1416.

20. DiMeglio DP \& Mattes RD (2000) Liquid versus solid carbohydrate: effects on food intake and body weight. Int J Obes Relat Metab Disord 24, 794-800.

21. van Dam RM \& Seidell JC (2007) Carbohydrate intake and obesity. Eur J Clin Nutr 61, Suppl. 1, S75-S99.

22. Singh GM, Micha R, Khatibzadeh S et al. (2015) Estimated global, regional, and national disease burdens related to sugar-sweetened beverage consumption in 2010. Circulation 132, 639-666.

23. Wittekind A \& Walton J (2014) Worldwide trends in dietary sugars intake. Nutr Res Rev 27, 330-345.

24. European Food Information Council (2005) The Determinants of Food Choice. EUFIC Review 04/2005. http://www. eufic.org/article/en/expid/review-food-choice/ (accessed November 2015).

25. Forshee RA \& Storey ML (2003) Total beverage consumption and beverage choices among children and adolescents. Int J Food Sci Nutr 54, 297-307.

26. Rampersaud GC, Kim H, Gao Z et al. (2014) Knowledge, perceptions, and behaviors of adults concerning nonalcoholic beverages suggest some lack of comprehension related to sugars. Nutr Res 34, 134-142.

27. Grimm GC, Harnack L \& Story M (2004) Factors associated with soft drink consumption in school-aged children. $J \mathrm{Am}$ Diet Assoc 104, 1244-1249.

28. Sutherland LA, Beavers DP, Kupper LL et al. (2008) Like parent, like child: child food and beverage choices during role playing. Arch Pediatr Adolesc Med 162, 1063-1069.

29. Irish Universities Nutrition Alliance (2006) National Teens' Food Survey. http://www.iuna.net/?p=29 (accessed November 2015).

30. Elgar FJ, Pfortner TK, Moor I et al. (2015) Socioeconomic inequalities in adolescent health 2002-2010: a time-series analysis of 34 countries participating in the Health Behaviour in School-aged Children study. Lancet 385, 2088-2095.

31. Heinen M, Murrin C, Daly L et al. (2014) The Childhood Obesity Surveillance Initiative (COSI) in the Republic of Ireland: Findings from 2008, 2010 and 2012. Dublin: Health Service Executive.

32. Celis-Morales C, Livingstone KM, Marsaux CF et al. (2015) Design and baseline characteristics of the Food4Me study: a web-based randomised controlled trial of personalised nutrition in seven European countries. Genes Nutr 10, 450.
33. Riboli E, Hunt KJ \& Slimani N (2002) European Prospective Investigation into Cancer and Nutrition (EPIC): study populations and data collection. Public Health Nutr 5, 1113-1124.

34. Irish Universities Nutrition Alliance (2004) National Children's Food Survey. http://www.iuna.net/?p=27 (accessed November 2015).

35. Irish Universities Nutrition Alliance (2011) National Preschool Nutrition Survey. http://www.iuna.net/?p=169 (accessed November 2015).

36. Irish Universities Nutrition Alliance (2011) Summary Report on Food and Nutrient Intakes, Physical Measurements, Physical Activity Patterns and Food Choice Motives from the National Adult Nutrition Survey. Irish Universities Nutrition Alliance; available at http://www.ucd.ie/t4cms/IUNA\% 20summaryreport_final.pdf

37. Kim SY \& Lee YJ (2009) Seasonal and gender differences of beverage consumption in elementary school students. Nutr Res Pract 3, 234-241.

38. Currie C, Zanotti C, Morgan A et al. (editors) (2012) Social Determinants of Health and Well-Being Among Young People. Health Behaviour in School-Aged Children (HBSC) Study: International Report from the 2009/2010 Survey. Health Policy for Children and Adolescents no. 6. Copenhagen: WHO Regional Office for Europe.

39. Duffey KJ, Huybrechts I, Mouratidou $T$ et al. (2012) Beverage consumption among European adolescents in the HELENA study. Eur J Clin Nutr 66, 244-252.

40. Forshee RA \& Storey ML (2003) Total beverage consumption and beverage choices among children and adolescents. Int J Food Sci Nutr 54, 297-307.

41. Vereecken CA, Inchley J, Subramanian SV et al. (2005) The relative influence of individual and contextual socioeconomic status on consumption of fruit and soft drinks among adolescents in Europe. Eur J Public Health 15, 224-232.

42. Bus AE \& Worsley A (2003) Consumers' health perceptions of three types of milk: a survey in Australia. Appetite $\mathbf{4 0}$, 93-100.

43. Carter RC (2002) The impact of public schools on childhood obesity. JAMA 288, 2180.

44. Vågstrand K, Linné Y, Karlsson J et al. (2009) Correlates of soft drink and fruit juice consumption among Swedish adolescents. Br J Nutr 101, 1541-1548.

45. van der Horst K, Kremers S, Ferreira I et al. (2007) Perceived parenting style and practices and the consumption of sugarsweetened beverages by adolescents. Health Educ Res 22, 295-304

46. Verzeletti C, Maes L, Santinello M et al. (2010) Soft drink consumption in adolescence: associations with food-related lifestyles and family rules in Belgium Flanders and the Veneto Region of Italy. Eur J Public Health 20, 312-317.

47. Rey-López JP, Vicente-Rodríguez G, Répásy J et al. (2011) Food and drink intake during television viewing in adolescents: the Healthy Lifestyle in Europe by Nutrition in Adolescence (HELENA) study. Public Health Nutr 14, 1563-1569.

48. van Ansem WJ, van Lenthe FJ, Schrijvers CT et al. (2014) Socio-economic inequalities in children's snack consumption and sugar-sweetened beverage consumption: the contribution of home environmental factors. Br J Nutr 112, $467-476$

49. Rockett HR, Berkey CS \& Colditz GA (2003) Evaluation of dietary assessment instruments in adolescents. Curr Opin Clin Nutr Metab Care 6, 557-562.

50. Lambert J, Agostoni C, Elmadfa I et al. (2004) Dietary intake and nutritional status of children and adolescents in Europe. Br J Nutr 92, Suppl. 2, S147-S211.

51. Livingstone MB, Robson PJ \& Wallace JM (2004) Issues in dietary intake assessment of children and adolescents. Br J Nutr 92, Suppl. 2, S213-S222. 